\title{
The Study on the Fund Procurement of City Steel Mill Removing Issues under the Background of Excessive Industrial Capacity Cutting Xiaojie Fan
}

\author{
North china electricity power university, Beijing, China
}

237937795@qq.com

\begin{abstract}
Keywords: Excessive industrial capacity cutting; Steel mill removing; The steel industry; Fund procurement
\end{abstract}

\begin{abstract}
As the first of the five economic tasks, it is obvious that the current situation of excessive industrial capacity cutting is serious. As the precursory industry under the excessive industrial capacity cutting, iron and steel industry attaches great importance of central government. In order to further promote the structural reform and pays special attention to the excessive industrial capacity cutting task of iron and steel industry, the country puts forward some suggestions within one is "Removing the city steel mill under the environmental protection ". And it faced many risks and challenges. This article is discussed mainly aimed at the fund-raising problems of moving.
\end{abstract}

\section{Introduction}

Iron and steel industry is the important basic raw material industry of national economy with strong investment promoting function and high industrial relevancy, which makes important contributions to Chinese economic and social development. In recent years, with the economy downward pressure, the demand of steel market has been dropped and the contradictions and problems have been exposed gradually during the rapid development of steel industry especially the excess production capacity. The differences in the production and management of iron and steel enterprises are aggravating and the percentage of loss-incurring enterprises is expanding. Moreover, under the serious environmental problems in today, as high energy consumption and high emission industries, it is extremely urgent for the iron and steel industry to move away from the city center to reduce the pressure of urban environment.

Now, much attention has been paid to the steel industry. One of the two industries of excessive industrial capacity cutting is steel. According to the Comment on resolving the over capacity of iron and steel industry to achieve the development by getting rid of poverty published by the state council, 45 million tons of excess capacity will be reduced this year in order to make steel product prices return to normal without low level competition and make the whole industry tend to be more healthy. From March 2016, Chinese steel prices began to rise and the amount of increase was about 1000 yuan. There is some fall but by the rebound in prices started in September 2016. According to data statistics of Sinosteel Corporation, the amount of increase of deformed steel bar used by the construction is $36 \%$ from the beginning of this year to the end of October while the cut deal used in ship is $42 \%$ and $36 \%$ in cold rolled coil plate used in car.

The main reason for this round of steel price increasing can be summarized into two aspects: first, on the demand side, one is the rise in steel demand expected due to the sales volume of large and medium-sized city commercial housing; Second, a lot of construction project is return to work after the break in winter which brings the demand growth of steel; Third, inventory supplement of the trader, which expanded the steel demand in the short term; Fourth, some policies such as the "supply the short board" and "steady growth" of market expectations will drive the steel demand; In the next place, on the supply side, one is the halt production of part steel mills last year that cause the steel production decline and reduce the market supply; Second, the market expectation of excessive industrial capacity cutting work will reduce steel production; third, part steel-producing region will take measures because of the major activities, which reduce the expected steel supply in short-term. In addition, the artificial speculation of spot and futures markets is also one of the 
important reasons of rapidly steel prices rising.

Steel market recovery has weakened the excessive industrial capacity cutting of enterprise. After a quite long period of the steel market downturn, the reversed transmission effect of market mechanism is emerging, and some enterprises have shut down or take the initiative to cut capacity due to operating difficulties. Under the unified national deployment, excessive industrial capacity cutting works have been developed. The government took a total decomposition, standard reversed transmission, financial support and a series of measures to strive to cut steel production capacity and achieve good progress step by step. Recently, the steel market warming is burning the hope of the industries which have stopped production or about to. It not only weakened the will of excessive industrial capacity cutting but also more and more enterprises begin to join in recovery production and increase production. If the trend continues on, it may be great offset for excessive industrial capacity cutting measures. If the pace of recovery production and increase production is speed up, the marginal effect will be weakened and the contradiction between supply and demand of the market may intensify again, which will led the industry into a mire of low efficiency once again.

Steel over capacity is not only the problems in its own but also a complex social problem faced by China. Five tasks had been proposed at the Central Economic Working Conference in 2016: cutting overcapacity, destocking, deleveraging, reducing costs and identifying growth areas. Put the cutting overcapacity as the first which can see the serious situation. In the new document published by the State Council in 2016 - Comment on resolving the over capacity of iron and steel industry to achieve the development by getting rid of poverty. The State Council put forward some opinions on further promoting the structural reform and paying special attention to the cutting overcapacity task of steel industry. One of them is "change the line of production to reduce capacity". To support the reduction and removing under the environmental protection for the industries, which have the condition and value to move?

In recent years, the nation has issued a lot of documents, and the Productivity Layout and Adjustment Planning of Iron and Steel Industry by the National Development and Reform Commission is another paper that is made by the government for the strategic adjustments for the whole industry, after the Policies on Iron and Steel Industry in 2005 and the Adjustment and Revitalization Plan of Iron and Steel Industry in 2009. In the first two documents, the first one was accused of too much emphasis on the expansion of steel production lines, which caused the increase in production capacity from 356 million tons to 770 tons, including nearly 400 tons that were produced without approval. As for the Adjustment and Revitalization Plan of Iron and Steel Industry that over focus on structural adjustment through mergers and reorganizations, the matched policies have not been issued.

If the relocation really begins, it will be the largest collective moving in the history of China's iron and steel industry, which involves 228 million tons of production capacity and accounts for $30 \%$ of the total one. But there are a lot of uncertainties for the relocation of steel factories. First, the State Council hasn't revoked the order that no new iron and steel projects are approved to build and it is unknown whether the relocation projects can get the approval documents. If the plants are distributed to the coastal regions more, it is a doubt that what kind of challenges the market and the large bloated steel industry will face. Second, there are several difficulties in the relocation. It generally takes five years at least from planning, choosing site, proving, building and production. That means it needs a longer time to achieve profitability after the completion of a new steel plant.

There are 75 key iron and steel enterprises in our country now within 18 are located in municipalities directly under the central government and provincial capital cities, and 34 in the big cities who have over million population. In accordance with the relevant data, there are 39 steel factories in the cities already planned to move, which will have a profound impact on the iron and steel industry in our country, urban layout, environmental protection, social development, relevant staff and residents. From the government, the countries offered that the iron and steel enterprises need to transfer to the coast and riverside places rapidly especially the steel mill which has uncoordinated development with the city. From the local government, the reason why the government asked the city steel factory to remove is the economic structure adjustment and the 
dissimilar environmental capacity. From the steel industry itself, due to the unreasonable area layout, city steel mills are faced with huge development pressure in logistics cost, environmental cost and artificial cost. From steel mills themselves, there is also a intrinsic motivation to optimize industry layout, rational allocation of resources, speed up the transformation and upgrading by removing. Anyway, it is a great test for the steel mill for the great investment and money investment from the planning, site selection, argumentation to complete and put into operation.

Take an example as the Shougang Group who has finished the relocation successfully at the end of 2010. In order to successfully move to Caofeidian, Shougang Group raised nearly 19 billion for the investment in Beijing-Tangshan Steel Company. The main fund is the special subsidies from national government and raised funds by steel mills. By pulling money from their existing assets, borrowing from the bank, retreating the land and the national subsidies, Shougang Group completed the construction of Caofeidian new steel mills and implementation plans of the workers.

For the steel mill which is removing, for example, Shijiazhuang iron and steel industry is determined to finish the relocation at the end of 2017 and moved to 70 kilometers west away from Shijiazhuang. For the funds required for the relocation, Yin Guangping, the deputy head of Department of Environmental Protection of Hebei province, has previously said that the steel relocation need about 30 billion yuan. For the huge funds, Wang Liang, the mayor of Shijiazhuang City said in the signing ceremony that because of the great significance of the relocation, the government would provide the biggest discounts on the policy for them. All the benefits, in addition to national charge, would use for the relocation work for them. Shijiazhuang Steel also signed bank and enterprise cooperation agreement with Hebei branch of China Construction Bank. The bank will provide larger capital support for the relocation of Shijiazhuang Steel. In addition, by land replacement, the original location after relocation through will be able to save a lot of spending for the relocation.

For Jinan Steel which is able to implement the adjustment, it requires at least 5 years from a draft plan, location, and construction to production if moving and needs at least 50 billion yuan. For the funds needed for the relocation, Jinan Steel will raise the special funds of eastern old industrial transferring and the main source is conformed to the relevant policies of state-owned land sales and other financial capital. Jinan Steel will also strive for the national development and reform commission which under the arrangement of NDRC as well as the special funds arranged by the national and provincial related department for industry development, pollution control, municipal infrastructure and service facilities construction. In addition, the municipal government will also support the qualified enterprises by the issuance of corporate bonds, medium-term notes and short-term financing bonds to raise funds for enterprise transferring.

Qingdao Steel sets up the old city relocation development fund to support the old enterprises transferring. The total amount of the fund is 11 billion yuan including: 3 billion yuan from the municipal investment group; 8 billion yuan from the public bidding which determine the relevant bank investment. Fund term is not more than seven years. The limited partnership funding enterprises which set up jointly by city investment group and the related bank is as the early stage of the relocation of Qingdao Steel. At present, the investment agreement has been signed and the first batch of 3 billion yuan has in place, which provides the fund guarantee for resettlement and loan repayment. Next, Qingdao finance will continue to focus on the fund operation condition and protect the enough funding timely and guide the enterprises to establish relocation funds combined with the circumstance and continuously optimize financing path for relocation.

Through the investigation and study about several steel mills, , it can be seen that the sources of funding of steel plant relocation mainly from the following aspects: one is the special subsidies of national government and transferring special funds arranged by the relevant government departments; Second, borrowing from the bank. Considering the policy, steel mills are still supported by the bank though the poor profit; Thirdly, all of the profits of the land leasing; Fourth, the steel mills raised himself apart from pulling money from their existing assets including the issuance of corporate bonds, medium-term notes and short-term financing bonds; Fifth, set up relocation development fund in addition to the Qingdao Steel mentioned above. Shougang also 
established Caofeidian development fund, infrastructure construction investment and capital funds of old industrial park. This is the useful exploring of financing ways of enterprise moving.

While pulling the bottom by the government of the billions of relocation money, various steel mills should also pay attention to strengthening fund management, save money spending simultaneously make fund-raising mode innovation with the aid of financing bonds, funds to ease the relocation fund pressure and achieve smooth relocation.

\section{References}

[1] L.p. Liu: Journal of business research, (2012) No.8 , p24

[2] C.1. Gao:Journal of business culture (2011)

[3] J.H. Li :Journal of business research, (2011) No.5, p 27

[4] Information on http://www.cs.com.cn/ssgs/gsxw/201508/t20150803_4769935.html

[5] Information on http://www.qlwb.com.cn/2016/0119/536729.shtml

[6] Information on http://www.dzwww.com/shandong/sdnews/201609/

[7] Information on http://www.dzwww.com/shandong/sdnews/201603/t20160306_13943082.htm

[8] Information on http://mt.sohu.com/20150911/n420882681.shtml

[9] Information on http://www.qlwb.com.cn/2016/0119/536729.shtml

[10]Wanberg C R, Zhu J, Kanfer R, et al. After the pink slip: Academy of Management Journal (2012) 